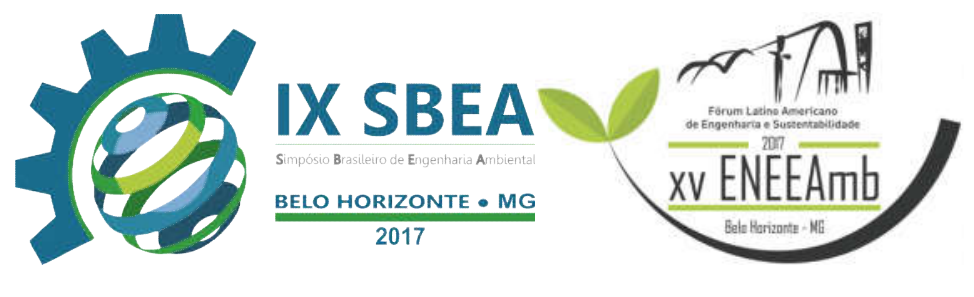

RESÍDUOS SÓLIDOS

\title{
VARIAÇÃO DA TEMPERATURA E REDUÇÃO DA MASSA NA COMPOSTAGEM DOMÉSTICA
}

Luciane Mara Cardoso Freitas - luciane.maracf@gmail.com

Universidade Federal do Ceara

Claudia Janaina Wieser- cwieser08@gmail.com

Universidade Federal do Ceara

Ronaldo Stefanutti - ronaldostefanutti@hotmail.com

Depto de Engenharia Hidraulica e Ambiental da Universidade Federal do Ceara 


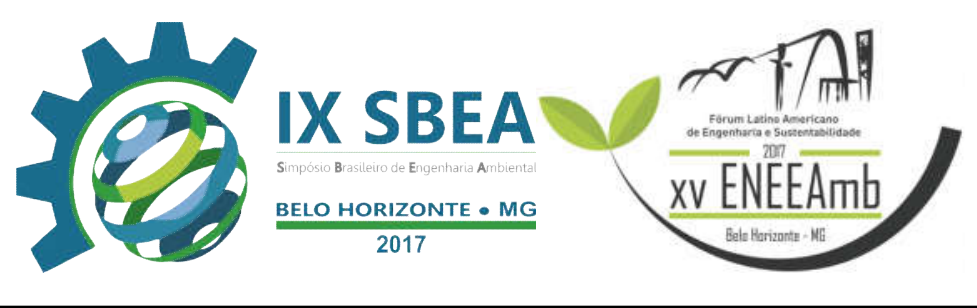

\section{RESUMO}

Um dos maiores problemas discutidos pela sociedade atualmente, no âmbito da sustentabilidade, é a coleta e a disposição final dos resíduos domésticos. O Brasil produz cerca de 215 mil toneladas de lixo por dia e não possui, em sua totalidade, um gerenciamento adequado para o descarte destes resíduos. O resíduo orgânico descartado merece atenção, pois corresponde a mais da metade do total gerado. Como alternativa de tratamento, a compostagem domiciliar pode contribuir para diminuir o volume de resíduos sólidos urbanos (RSU) descartados pela sociedade. Este trabalho apresenta uma pesquisa realizada para avaliar um sistema de compostagem doméstica utilizando restos de alimentos gerados no restaurante universitário da UFC, o suficiente para simular a geração de resíduos de uma família com 4 pessoas, para alimentar 36 composteiras. Usando uma Bag e recipientes de plástico, quadrados e redondos, foi analisada a influência da temperatura durante o processo de decomposição da matéria orgânica e sua relação com a redução de massa nas composteiras. A metodologia utilizada testa a poda, a serragem e a grama como materiais estruturantes, além de testes-controle sem adição de material estruturante. Todas as composteiras apresentaram elevação de temperatura, porém foi inferior a $55^{\circ} \mathrm{C}$ indicando que ocorreu o processo da compostagem e tiveram uma redução de massa de até 93\%. Esta pesquisa trouxe resultados coerentes e que inter-relacionam a influência da temperatura e da redução de massa na decomposição da matéria orgânica, indicando a melhor maneira de se conduzir um processo de compostagem doméstica.

Palavras-chave: compostagem doméstica, temperatura, redução de massa.

\section{INTRODUÇÃO/OBJETIVO}

O Brasil tem apresentado problemas recorrentes quando se trata de coleta e disposição adequada de resíduos sólidos, por isso muitas discussões sobre esse tema fazem parte dos grandes eventos políticos e científicos. De acordo com a ABRELPE (2014), são produzidas no País cerca de 215 mil toneladas de resíduos sólidos por dia e a tendência é aumentar. Muitas vezes, os impactos gerados por esse problema são 


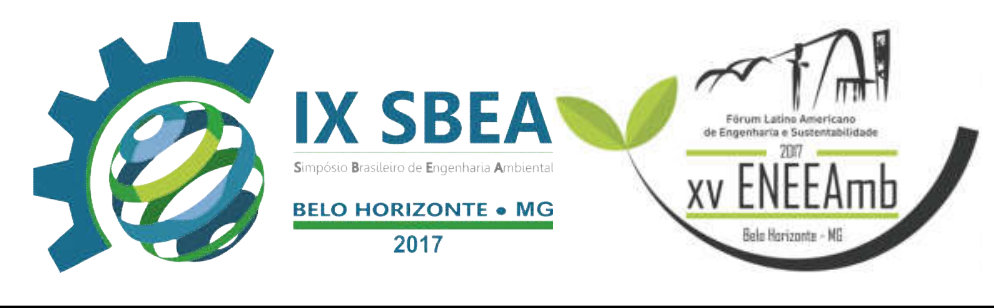

negativos, comprometendo o meio ambiente e o desenvolvimento socioeconômico da população.

Uma importante diretriz para a gestão de resíduos sólidos no âmbito político e legal é a Política Nacional de Resíduos Sólidos (PNRS), Lei no 12.305 de 2010. Ela tem como meta a redução da quantidade de resíduos e rejeitos gerados, sendo estes encaminhados para a disposição final ambientalmente adequada. A realidade do País é que 58,4\% do total dos resíduos vão para aterros sanitários (ABRELPE, 2014), entretanto como foi dito, boa parte dessa percentagem é constituída de material orgânico com potencial valor agregado.

Deste modo, aumentar o número de aterros sanitários não é a solução do problema, pois os aterros sanitários têm capacidade limitada e altos custos de manutenção envolvidos. Sendo assim, buscas por metodologias que contribuam para o desenvolvimento sustentável da sociedade e com vistas a atingir as metas da PNRS são necessárias. O resíduo sólido doméstico brasileiro é composto por cerca de $51 \%$ de matéria orgânica (IPEA, 2012) e a compostagem surge então como uma importante alternativa para o descarte da mesma.

Na compostagem, a matéria orgânica é transformada a partir de um processo biológico em substâncias húmicas, resultando em um produto ideal para ser usado na agricultura sem causar danos ambientais (SOUZA et al., 2001). Mano et al. (2005) afirmam que a compostagem "consiste na estabilização biológica da matéria orgânica pela ação controlada de microorganismos, para transformá-la em compostos ou húmus”.

Ao longo do processo de degradação biológica da matéria orgânica durante a compostagem, ocorre uma elevação na temperatura devido às atividades microbianas. Cada grupo de organismos que atua degradando a matéria tem uma faixa de temperatura ótima para o seu metabolismo. Deste modo, muitos pesquisadores consideram a temperatura como o fator mais indicativo do equilíbrio biológico no composto em decomposição e o mais importante indicador da eficiência do processo de compostagem (PEREIRA NETO, 1988 apud VALENTE et al., 2008).

Sendo assim, este trabalho tem como objetivo avaliar o comportamento da temperatura e a redução de massa em composteiras domésticas, usando uma 


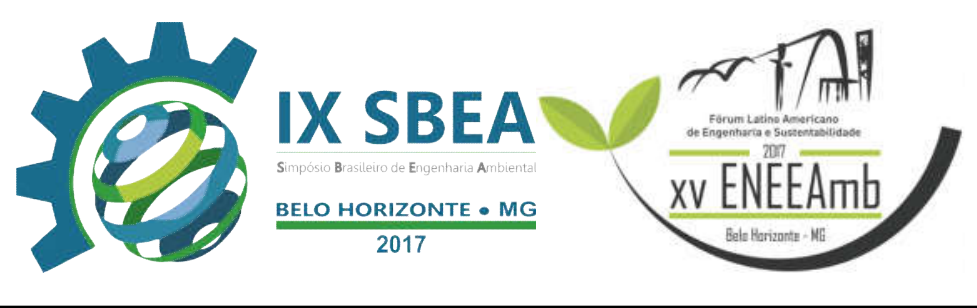

metodologia de fácil acesso a população e com pouca mão-de-obra necessária no processo.

\section{METODOLOGIA}

O experimento foi conduzido na Horta didática do Departamento de Fitotecnia, no Campus do Pici, na Universidade Federal do Ceara (UFC) (Latitude 3 44'22,3" S e Longitude 38 34’34,4” O). Foram utilizados os resíduos orgânicos produzidos no Restaurante Universitário da UFC como fonte principal de nitrogênio no processo de compostagem. As composteiras foram abastecidas com as sobras de refeições e os restos de comida dos pratos dos usuários.

Os recipientes usados para a montagem das composteiras foram: Bags reutilizáveis confeccionadas em polipropileno, com volume de $135 \mathrm{~L}$ e cestos de plástico em dois formatos, redondos com $70 \mathrm{~L}$ e quadrangular de $45 \mathrm{~L}$. Os cestos eram perfurados, comumente utilizados em residências para armazenar roupas, revestidos por tela mosquiteiro para evitar a entrada de roedores e baratas. Foram montadas 12 composteiras de cada modelo, com 3 repetições, totalizando 36.

Nessa configuração, foram testados três tipos de material vegetal, ricos em carbono, com função de estruturante, a saber: poda de árvore picada, grama seca e serragem. Foram introduzidos também na avaliação, testes-controle utilizando apenas o resíduo orgânico de alimentos sem adição de material estruturante. Para simular um projeto de composteira caseira foram introduzidas, durante a operação da compostagem, cinco vezes por semana, quantidades equivalentes à produção de resíduo orgânico por uma família de até 4 pessoas (cerca de $2,7 \mathrm{Kg}$ ).

O resíduo orgânico depositado era misturado manualmente e pesado. Duas vezes por semana foram adicionados cerca de 1,2L de água em cada composteira para controle de umidade. Esse procedimento de abastecimento de resíduos durou até o $60^{\circ}$ dia, quando o volume total do maior recipiente utilizado como composteira foi preenchido.

As temperaturas foram medidas em cada unidade experimental de segunda a sexta-feira durante a fase termofílica (até 71 dias) e, após esse período, eram medidas 2 


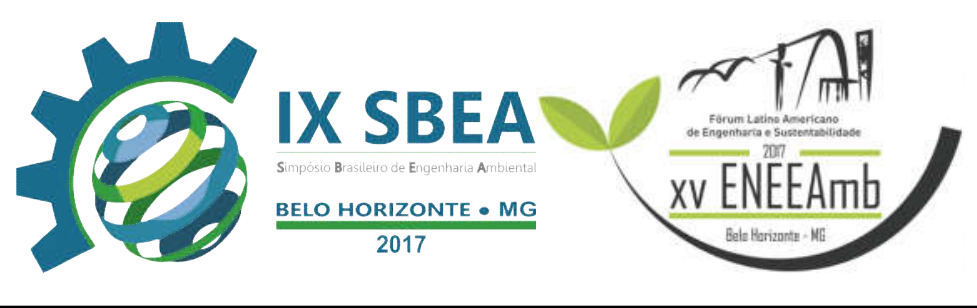

vezes por semana devido à estabilização da temperatura do sistema. Nesses períodos citados o termômetro foi posicionado a $15 \mathrm{~cm}$ do fundo. Para tais medidas, utilizou-se um termômetro do tipo termopar com sonda de $1 \mathrm{~m}$. Os parâmetros monitorados para avaliar a produção do adubo orgânico foram: $\mathrm{pH}$, umidade, relação $\mathrm{C} / \mathrm{N}$ e temperatura.

As amostras de cada composteira eram retiradas a $0,15 \mathrm{~m}$ do fundo do recipiente, e foram feitas 8 coletas para análise nos seguintes tempos de reação: $0,7^{\circ}$ dia, $15^{\circ}$ dia, $30^{\circ}$ dia, $45^{\circ}$ dia, $60^{\circ}$ dia, $90^{\circ}$ dia, $120^{\circ}$ dia. As amostras eram levadas para o Laboratório de Saneamento Ambiental (LABOSAN) da Universidade Federal do Ceará onde foram conduzidas as análises necessárias.

\section{RESULTADOS E DISCUSSÃO}

De acordo com Kiehl (1998) durante a compostagem é possível observar três fases distintas: uma fase inicial mais rápida de composto imaturo ou cru, caracterizada pela formação de ácidos orgânicos e toxinas; depois a fase de semicura ou bioestabilização e, finalmente, uma terceira fase, a de maturação do composto. As temperaturas se comportam de forma diferente em cada etapa.

Segundo Pereira et al. (1989) durante o processo de compostagem existem três fases de mudança de temperatura: mesofílica, termofílica e de maturação. Inicialmente, a decomposição da matéria orgânica é conduzida por micro-organismos mesófilos de metabolismo exotérmico. Durante a oxidação da matéria orgânica parte do calor gerado acumula-se no interior da composteira, elevando a temperatura (KIEHL, 1985). De acordo com Denardin et al. (2010) esta fase ocorre em temperaturas entre $15^{\circ} \mathrm{C}$ e $45^{\circ} \mathrm{C}$.

Quando a temperatura se eleva, ultrapassando os $45^{\circ} \mathrm{C}$, a atividade microbiológica mesofílica é suprimida pela implantação de uma comunidade microbiana termofílica (NOGUEIRA E COSTA, 2011). Durante a fase termofilica a temperatura pode chegar até a $70^{\circ} \mathrm{C}$, depois por auto-limitação dos termofílicos, a temperatura começa a diminuir e volta a predominar atividade mesofílica.

Analisando as temperaturas das composteiras R1 durante todo o processo (Gráfico 1) constatou-se que, durante os primeiros dias, todas atingiram uma temperatura de $40^{\circ} \mathrm{C}$ caracterizando a fase mesofilica, como apresentado por Kiehl 


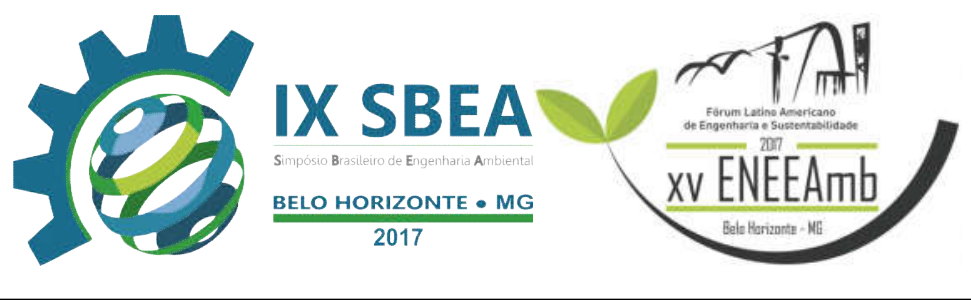

(2012). Todos as composteiras, exceto o controle (R1-C), tiveram picos de temperatura acima de $45^{\circ} \mathrm{C}$ caracterizando início do processo termofilico, obtendo degradação máxima e estabilização da matéria orgânica (ARVANITOYANNIS et al., 2008).

As composteiras R1-G e R1-S atingiram as máximas de $53,40^{\circ} \mathrm{C} \pm 1,47 \mathrm{e}$ $53,00^{\circ} \mathrm{C} \pm 3,97$, respectivamente, porém não alcançaram $55^{\circ} \mathrm{C}$ o que demonstrou a não necessidade de revolvimento do material. De acordo com Kiehl (1985) as altas temperaturas no processo de compostagem são importantes por favorecer a eliminação de organismos patogênicos que não resistem por muito tempo à temperaturas próximas de 50 a $60^{\circ} \mathrm{C}$.

Gráfico 1- Variação Média de Temperatura na Região Inferior do Recipiente R1

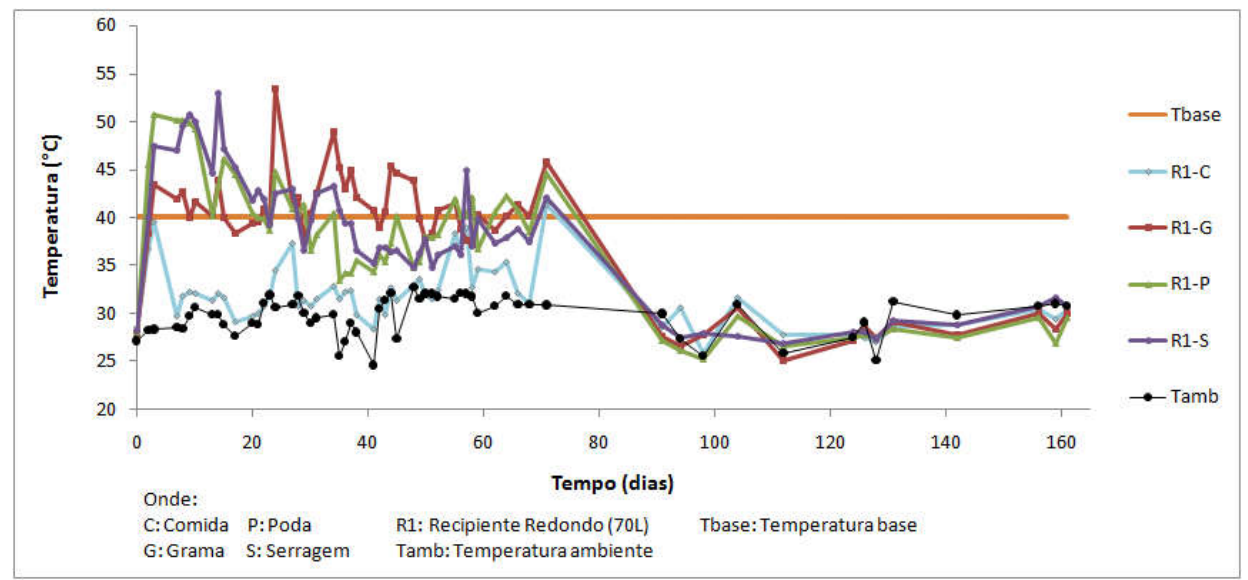

A temperatura das composteiras do R2 (Graf 2) atingiram valores inferiores aos da $\mathrm{R} 1$, com máximas de $40,6^{\circ} \mathrm{C} \pm 1,04 ; 45,17^{\circ} \mathrm{C} \pm 2,87 ; 48,53^{\circ} \mathrm{C} \pm 2,64 ; 46,77^{\circ} \mathrm{C} \pm 3,72$, respectivamente para os materiais C, G, P e S. Segundo Colon et al. (2010) essa variação ocorreu pois, durante o processo de compostagem caseira, a quantidade de material é baixa para armazenar grande quantidade de calor, ou seja, recipientes com volumes menores tem um baixo isolamento térmico, facilitando a sua dissipação. 

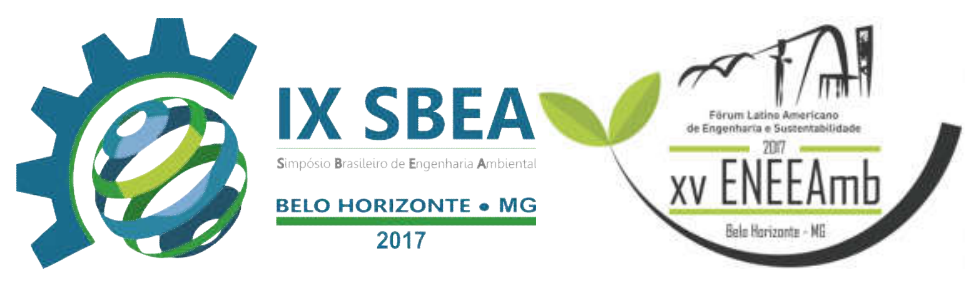

Gráfico 2- Variação Média de Temperatura na Região Inferior do Recipiente R2

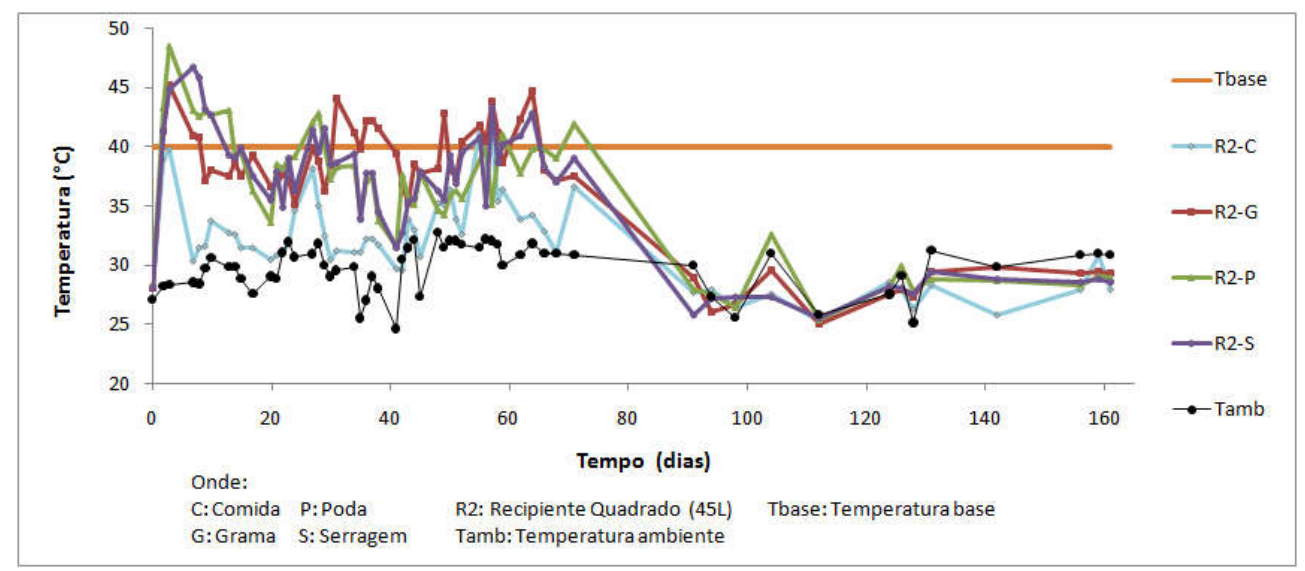

As composteiras do R3 (Graf 3) mantiveram a temperatura acima dos $40^{\circ} \mathrm{C}$ durante mais tempo quando comparadas as do R1 e R2, indicando maior permanência na fase termofílica, com máximas de $51,47^{\circ} \mathrm{C} \pm 3,72$ para $\mathrm{Ge} 49,67^{\circ} \mathrm{C} \pm 10,06$ para $\mathrm{S}$. A composteira alimentada apenas com comida (R3-C) obteve os menores valores de temperatura, não alcançando nem os $40^{\circ} \mathrm{C}$. Tal resultado é reflexo da ausência de material estruturante no composto, fonte de carbono.

Gráfico 3- Variação Média de Temperatura na Região Inferior do Recipiente R3

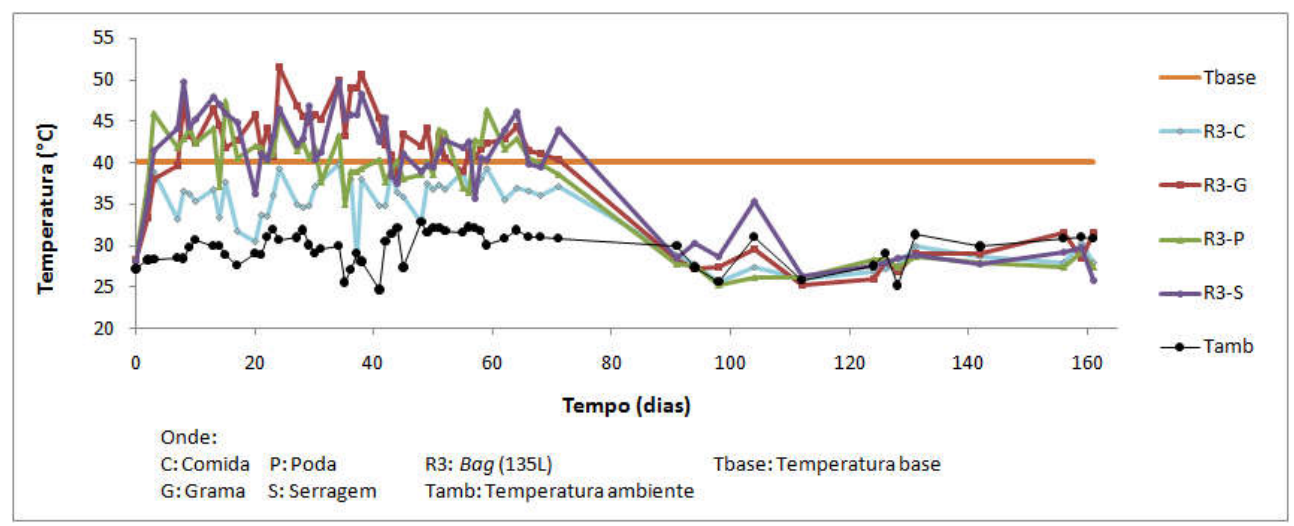

O comportamento da temperatura em todos os recipientes apresentou oscilações abruptas compatíveis com a metodologia adotada de alimentação diária das composteiras. À medida que a massa total reduzia e parte da biomassa passava para a 


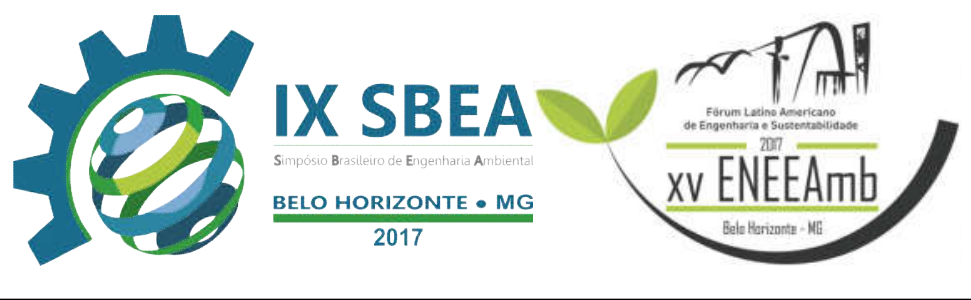

fase mesófílica, o material mais recentemente adicionado nas camadas superiores iniciava o processo de degradação, gerando nova fase termofílica, ocasionando os picos de temperatura obtidos. Colon et al. (2010) também encontraram resultados semelhantes com emprego de uma metodologia de alimentação semanal, obtendo picos de temperatura durante o processo. Entretanto, Loureiro et al. (2007), que avaliaram composteiras alimentadas uma única vez, a temperatura se comportou de modo mais estável.

A Tabela 1 revela que a quantidade de material resultante na massa final é baixa, principalmente nas composteiras com comida, as quais também obtiveram temperaturas abaixo das recomendadas. Todos os recipientes favoreceram a redução significativa de massa, independente do estruturante empregado, obtendo valores superiores a $82 \%$. Entretanto, Karnchanawong e Nissaikla (2014) que utilizaram composteiras de 200L com resíduos de comida e de folhas obtiveram, após 150 dias de compostagem, reduções na faixa de 63 a 73\%. No presente trabalho, a redução mais significativa pode ser atribuída ao tipo de processo adotado.

Tabela 1- Redução final da massa após a compostagem

\begin{tabular}{ccccc}
\hline Recip. & Estrut. & Massa Inicial (Kg) & Massa Final* $(\mathbf{K g})$ & Redução (\%) \\
\hline R1 & C & 90,15 & 1,14 & 98,18 \\
R1 & G & 71,20 & 1,27 & 96,68 \\
R1 & P & 73,87 & 4,77 & 83,67 \\
R1 & S & 99,07 & 3,37 & 90,06 \\
R2 & C & 85,14 & 1,21 & 98,01 \\
R2 & G & 65,48 & 1,03 & 96,43 \\
R2 & P & 68,33 & 3,18 & 87,01 \\
R2 & S & 53,73 & 2,15 & 91,19 \\
R3 & C & 117,71 & 1,05 & 98,94 \\
R3 & G & 98,89 & 4,44 & 92,85 \\
R3 & P & 165,62 & 12,83 & 82,84 \\
R3 & S & 150,95 & 14,32 & 84,83 \\
\hline
\end{tabular}

A compostagem provoca uma redução do volume da biomassa inicial de 25 a $50 \%$, devido tanto à evaporação de água como à degradação da matéria orgânica, transformando partículas mais grossas em finas (VALLINI, 1995 apud CORDEIRO, 


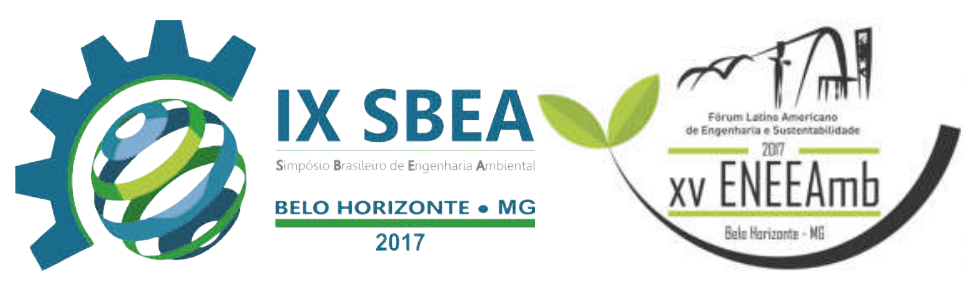

2010). De acordo com Kiehl (1998) a redução de massa na compostagem domiciliar deve ser superior a $50 \%$ o que indica o sucesso do processo de decomposição.

\section{CONCLUSÕES/RECOMENDAÇÕES}

O processo adotado de compostagem mostrou ser eficiente na redução de volume dos resíduos orgânicos, enfatizando que a temperatura é um parâmetro eficaz para indicar o processo. Entre as composteiras testadas, a de $75 \mathrm{~L}$ e a de $135 \mathrm{~L}$ foram mais eficientes para o processo, uma vez que permaneceram mais tempo em temperaturas acima de $40^{\circ}$. As composteiras domésticas confeccionadas foram de baixo custo e com materiais de fácil acesso para a população.

\section{REFERÊNCIAS BIBLIOGRÁFICAS}

ARVANITOYANNIS, I. S.; KASSAVETI, A.; LADAS, D. Food Waste Treatment Methodologies. Waste Management for the Food Industries, 2008.

ASSOCIAÇÃO BRASILEIRA DE EMPRESAS DE LIMPEZA PUBLICA E RESÍDUOS ESPECIAIS. Panorama dos resíduos sólidos no Brasil 2014. Disponível em: $<$ http://www.abrelpe.org.br/Panorama/panorama2014.pdf $>$. Acesso em: 09 de julho de 2016.

COLON, J.; MARTÍNEZ-BLANCO, J.; GABARRELL, X.; ARTOLA, A.; SANCHEZ, A.; RIERADEVALL, J.; FONT, X. Environmental assessment of home composting. Resour. Conserv. Recyl., 54, p. 893-904, 2010.

CORDEIRO, N. M. Compostagem de Resíduos Verdes e Avaliação da Qualidade dos Compostos Obtidos - Caso de Estudo da Algar S.A. Dissertação (Mestrado em Engenharia do Ambiente - Tecnologias Ambientais) Instituto Superior de Agronomia, Universidade Técnica de Lisboa, Lisboa, 2010.

DENARDIN, G. P.; WOLFF, D. B. E. VASCONCELlOS, N. J. S. Solid Waste: The Quantity of Recyclable Waste Lost in Days of Surplus in The Plant. Disc. Scientia. Série: Ciências Naturais e Tecnológicas, S. Maria, v. 11, n. 1, p. 1-16, 2010.

INSTITUTO DE PESQUISA E ECONOMIA APLICADA. Diagnóstico dos resíduos sólidos. Relatório de pesquisa, 2012.

KARNCHANAWONG, S.; NISSAIKLA, S. Effects of microbial inoculation on composting of household organic waste using passive aeration bin. International Journal Of Recycling Of Organic Waste In Agriculture, v. 3, n. 4, p.113-119, 4 set. 2014. DOI:10.1007/s40093-014-0072-0. 


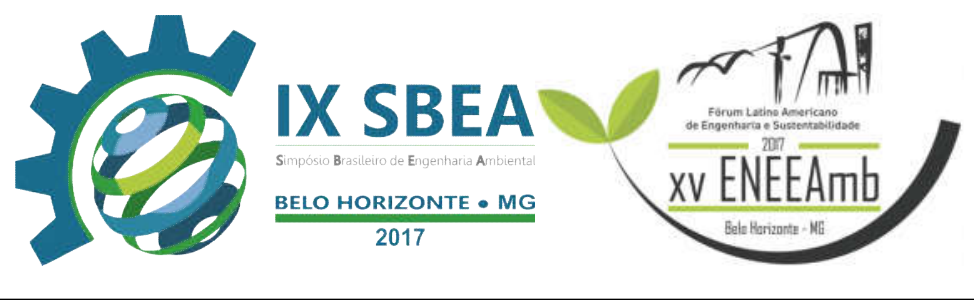

KIEHL, E. J. Fertilizantes Orgânicos.Piracicaba: Editora Ceres, 1985.

KIEHL, E. J. Manual de Compostgem. Piracicaba: Editora Ceres, 1998.

KIEHL, E. J. Manual de compostagem: maturação e qualidade do composto. 3.ed. Piracicaba: Ed. Agronômica Ceres, 2012. 171p.

LOUREIRO, D. C.; AQUINO, A. M.; ZONTA, E.; LIMA, E. Compostagem e vermicompostagem de resíduos domiciliares com esterco bovino para a produção de insumo orgânico. Pesquisa agropecuária. Brasília, v.42, n.7, p.1043- 1048, jul. 2007.

MANO, E B; PACheCO, E B A V; BONELli, C M C. Meio Ambiente, Poluição e Reciclagem. 1 ed. São Paulo: Edgard Blücher, 2005.

NOGUEIRA, W. A.; COSTA, D. D. Variação da temperatura na compostagem de resíduos sólidos orgânicos. 2011. México. Disponível em: <www.bvsde.paho.org/bvsaidis/resisoli/mexico/03458p04.pdf $>$ Acesso em: 29 de Maio de 2017.

PEREIRA NETO, J. T., 1996: Manual de Compostagem.Belo Horizonte - UNICEF $56 \mathrm{p}$.

SOUZA, F.A. de; AQUINO, A.M. de; RICCI, M. dos S.F.; FEIDEN, A. Compostagem. Seropédida: Empresa Brasileira de Pesquisa Agropecuária - Embrapa Agrobiologia, 11 p., 2001 (Boletim Técnico, nº 50).

VALENTE, B. S.; XAVIER, E. G.; CABRERA, B. R.; MORSELli, T. B. G. A.; MORAES P. de O.; JAHNKE, D. S.; LOPES, D. C. N.; BRUM JR, B. de S. Fatores que afetam o desenvolvimento da compostagem de resíduos orgânicos. Archivos de zootecnia, Pelotas, v.58®, p. 59-85, 2009. 